REVISTA ANDALUZA DE ANTROPOLOGÍA

NÚMERO 15: ACTIVIDADES TURÍSTICAS, CIUDAD Y PATRIMONIO CULTURAL: MIRADAS CRÍTICAS. TOURIST ACTIVITIES, CITY AND CULTURAL HERITAGE: CRITICAL GLANCES SEPTIEMBRE DE 2018

ISSN 2174-6796

[pp. 156-182]

http://dx.doi.org/10.12795/RAA.2018.15.07

\title{
PATRIMONIO CULTURAL, PLANES DE DESARROLLO RURAL Y TURISMO EN LA ISLA DE LA GOMERA
}

\author{
Patricia García Alfonso \\ Universidad Nacional de Educación a Distancia (UNED Málaga)
}

\section{Resumen.}

La identificación de los elementos culturales en las zonas rurales de la isla de la Gomera y el análisis realizado sobre las iniciativas empresariales subvencionadas por los planes de desarrollo rural establecen y refuerzan la importancia del patrimonio local como recurso capaz de generar productividad. En unos espacios donde el sector primario pierde su importancia, algunas de estas iniciativas se presentan como fuente de generación de actividad económica y en muchos casos como elementos de activación del patrimonio. Esta realidad unida a la riqueza del paisaje y de las tradiciones sirve como reclamo para numerosos turistas y lleva a establecer nuevas líneas futuras de trabajo que relacionan planes de desarrollo, patrimonio y turismo a través del estudio de casos.

Este artículo pretende a través de la investigación etnográfica establecer los efectos que, en general, y sobre el patrimonio tienen los Planes de Desarrollo Rural y realizar propuestas de actuación. El objetivo último es contribuir a mantener estos espacios rurales únicos y sus elementos culturales.

Palabras claves.

Identidad, planes de desarrollo rural, patrimonio, turismo, La Gomera. 


\begin{abstract}
.
The identification of cultural elements in the island of La Gomera and the subsequent analysis of entrepreneurial initiatives set by rural development plans establish and reinforce the value of the local heritage as a productivity generating resource. In spaces where the primary sector loses its importance, some of these initiatives are presented as elements which activate the heritage. This reality in conjunction with the richness of the natural landscape and traditions, become an active attraction for a high number of tourists and leads to establish new lines of research between development, heritage and tourism through the study of cases.

This article aims through ethnographic research to establish the effect that, in general, and about the heritage has the rural development and to make proposals for improving. The aim is to contribute to preservation of these unique rural spaces and their cultural elements.
\end{abstract}

Key words. Identity, Rural Development Plans, Heritage, Tourism, La Gomera

\title{
1. INTRODUCCIÓN
}

El patrimonio entendido como una construcción social requiere siempre un proceso de legitimación y consenso y su carácter simbólico parte de su capacidad para representar una identidad (Prat, 1997:22). Este patrimonio, por tanto, no existe hasta que no se construye un discurso y da a conocer los valores con los que se asocia y que justifica ese compartir colectivo que provoca su preservación (Agudo, 2012).

Esta identidad es también un hecho dinámico pero con un nivel de permanencia que tiene en la mayoría de los casos un origen y evolución en la historia (Agudo, 2012) y que, dependiendo de la centralidad e importancia que ocupa en la comunidad tiene mayor o menor permanencia.

La historia aparece en numerosos autores como necesaria para comprender los problemas que estudiamos dentro del presente (Narotzky, 2001, Godelier, 1987, Wolf, 2014, Roseberry, 2014, Comas, 1988) y esa estructura histórica tiene a su vez una dimensión local y global. Hobsbawn (2012) hacía referencia a que muchos elementos viejos son la base para construir nuevas tradiciones y esto refleja el carácter dinámico de la cultura. Greenwood (2001) por su parte puntualizaba que, muchas cosas cambian justamente cuando la gente las quiere conservar y otras muchas son invencibles y esa es la dificultad de analizar el cambio.

Esta construcción social de la realidad entendida como un universo simbólico, ordena la historia y ubica los acontecimientos colectivos dentro de una unidad coherente, que 
incluye, el pasado, el presente y el futuro y para entender su significado tendremos que entender la historia de su producción (Berger y Luckmann, 2011:131). En el caso de la investigación realizada en las zonas rurales de la Gomera (García, 2016) se constata como esa identidad es plural y global, pero también individual y colectiva, rastreados esos elementos culturales a través de la historia y compartidos por la población lo que le proporciona una importancia aún mayor. El concepto por tanto de cultura se entiende como procesos que construyen, reconstruyen y desmantelan elementos culturales (Wolf, 2014).

El debate acerca de lo qué es y no es patrimonio merece también una consideración puesto que de ello depende su importancia como elemento de identidad y su confrontación o no con la propia comunidad. El recorrido sobre la legislación tiene un foco central en la ley de 1985 sobre el Patrimonio Cultural Español porque en ella ya se habla de patrimonio etnológico como conocimientos, actividades y no sólo de aspectos materiales sino sociales y espirituales (García, 1998:13).

En este ámbito entramos de lleno en las cuestiones relativas a quién es capaz de promover una reactivación patrimonial. En esta línea, los poderes políticos juegan un papel determinante, pero no solamente ellos como veremos más adelante, la sociedad civil, tiene mucho que decir.

El patrimonio, por tanto, más allá de su carga simbólica y cultural adquiere un valor añadido, una rentabilidad económica y puede actuar como motor de dinamización económica.

La pérdida de importancia de las actividades agrícolas y ganaderas en unos espacios como los de la Isla de La Gomera han impulsado numerosos planes de desarrollo en los cuales, entre otras medidas, el patrimonio se constituye como un importante recurso turístico.

En esta línea, y haciendo referencia a financiaciones del medio rural, la política agraria común experimenta un enorme cambio desde los años 90 para dirigir las actividades a espacios rurales que adquieren nuevas funciones y que responde a las demandas de una sociedad más globalizada (Beck, 1986).

Los Planes de Desarrollo Rural (PDR) en la isla de La Gomera subvencionados por los Fondos FEADER constituyen un ejemplo de fomento de reactivación patrimonial y de generación de actividad económica.

Por otro lado, los cambios en las tendencias del turismo envuelto en el marco de la globalización acentúan las diversificaciones de la activación patrimonial en relación a esos "nuevos turismos" que buscan en la cultura esa identidad y autenticidad (Prat, 2011, Aguilar et al., 2003). 
La cultura local se convierte en un elemento fundamental de la oferta turística y también impregna todos los textos oficiales sobre desarrollo local. Los Fondos Europeos se constituyen como elementos imprescindibles de esa dinamización económica que le puede dar un valor importante al medio rural (Aguilar et al., 2003).

La tesis central de este artículo se basa principalmente en analizar los efectos socioeconómicos y culturales que tienen los proyectos empresariales y centros de interpretación subvencionados por Fondos Europeos con la iniciativa LEADER para la reactivación del patrimonio. Para ello analizaremos varios proyectos empresariales seleccionados del periodo 2007-2014 en función de su relación directa con varios de los elementos culturales identificativos de la isla. Así mismo, de forma secundaria, reflexionaremos acerca de las relaciones entre patrimonio, turismo y planes de desarrollo. Esto servirá de base para un primer análisis exploratorio ya que muchos de estas iniciativas inciden directamente o indirectamente en el turismo. Este estudio revela el alcance que tiene este tipo de iniciativas en el mantenimiento de actividades tradicionales, difusión de la cultura, preservación de elementos culturales, generación de empleo o mantenimiento de la población entre otros efectos. La metodología utilizada para este estudio ha sido principalmente cualitativa a través de entrevistas semiestructuradas y observación participante.

La estructura del artículo se centra como marco introductorio en las relaciones entre patrimonio e identidad para, posteriormente, contextualizar el patrimonio natural y cultural de la isla a través de sus recursos y elementos culturales. Las relaciones entre activación del patrimonio y Planes de Desarrollo Rural se muestran a través del estudio de casos analizados en la investigación etnográfica; posteriormente se establecen las interrelaciones entre turismo y patrimonio. Finalmente las conclusiones permiten realizar algunas propuestas basadas en el trabajo de campo sobre los efectos de estas iniciativas en la preservación del Patrimonio.

\section{EL CONTEXTO DE LA ISLA DE LA GOMERA: PATRIMONIO NATURAL Y} CULTURAL

La isla de La Gomera presenta en su marco geográfico una vertiente norte abrupta y escabrosa y perfiles suaves en el sur; es la isla más erosionada del archipiélago Canario y la segunda más pequeña después del Hierro. Una isla marcada por enormes contrastes en su medio natural y con una gran riqueza a través de sus bosques de laurisilva que forman el Parque Nacional de Garajonay y que atrae constantemente a gran cantidad de turistas. Estos bosques unidos a una profunda relación del hombre con este medio dan a la isla de la Gomera una singularidad única. Las fuertes pendientes de su relieve obligaron 
al hombre a construir bancales para poder aprovechar todos los espacios posibles de cultivo formando a su vez a especialistas artesanos en la piedra. Una isla cuya actividad económica ha sido hasta hace relativamente poco tiempo agrícola y ganadera, marcada profundamente por la propiedad de la tierra y cuyo poblamiento estaba condicionado también por las dificultades de su relieve (Burriel, 1982). La pérdida de población es constante y muy especialmente en las zonas de medianías (alturas a partir de los 300 metros) con un agudo envejecimiento de la población. Su evolución poblacional ha estado marcada por los grandes procesos migratorios a Cuba, Venezuela y a partir de los años 60 al sur de Tenerife.

Las densas descripciones realizadas por diferentes autores nos proporcionan información sobre los modos de producción, actividad económica, población, costumbres y rituales en diferentes etapas, (Díaz y Rodríguez, 1990, Reyes, 1989, Trapero, 2000, Juan de Castro Ahíta, 1856) o sobre su historia, (Bethencourt, 1881, Viera y Clavijo, 2010, Álvarez, 1960) que nos permiten contextualizar y analizar los elementos culturales que permanecen hoy. La relación del hombre con el paisaje se materializa en montañas y bancales como ejemplo del aprovechamiento de un espacio que poco a poco queda abandonado. Las actividades complementarias a los sistemas de producción agrícolas y ganaderos se materializan a través de una enorme variedad de artesanos que trabajan desde el barro, textil, madera, piedra o cestería y cuyos conocimientos han pasado a través de generaciones.

Costumbres que rodean la evolución de la población desde el pasado y marcado por una dureza en las formas de vida en la cual el "Don" (Mauss, 2009), esa obligación de dar y recibir generaba fuertes relaciones sociales que servían para soportar épocas de mayores dificultades. En este sentido, los intercambios de un producto por otro y las enormes distancias que se recorrían a pie son inseparables de su historia. Los elementos de la gastronomía se convierten en parte de su cultura, la elaboración y el ahumado del queso, la miel de palma, la fabricación de vino y hasta las tortas de helechos en épocas de hambre son símbolos identificativos de la población.

Los instrumentos musicales como el tambor y las chácaras fabricadas por los propios artesanos son elementos importantes de las tradiciones y de su folclore, y el baile del tambor hace que se conserve en la isla el mejor repertorio romancístico.

Estos elementos de la superestructura conductual como identificaría Marvin Harris, a través de la danza y la música se configuran como elementos de identidad de la población gomera y adquieren su nivel más evidente en las manifestaciones religiosas (García, 2016).

Estas procesiones religiosas son momentos simbólicos y la participación de la población en ellas es una reafirmación de su identidad (Briones, 1991). 
Tabla 1: Elementos identificativos de la población de medianías en la isla de La Gomera

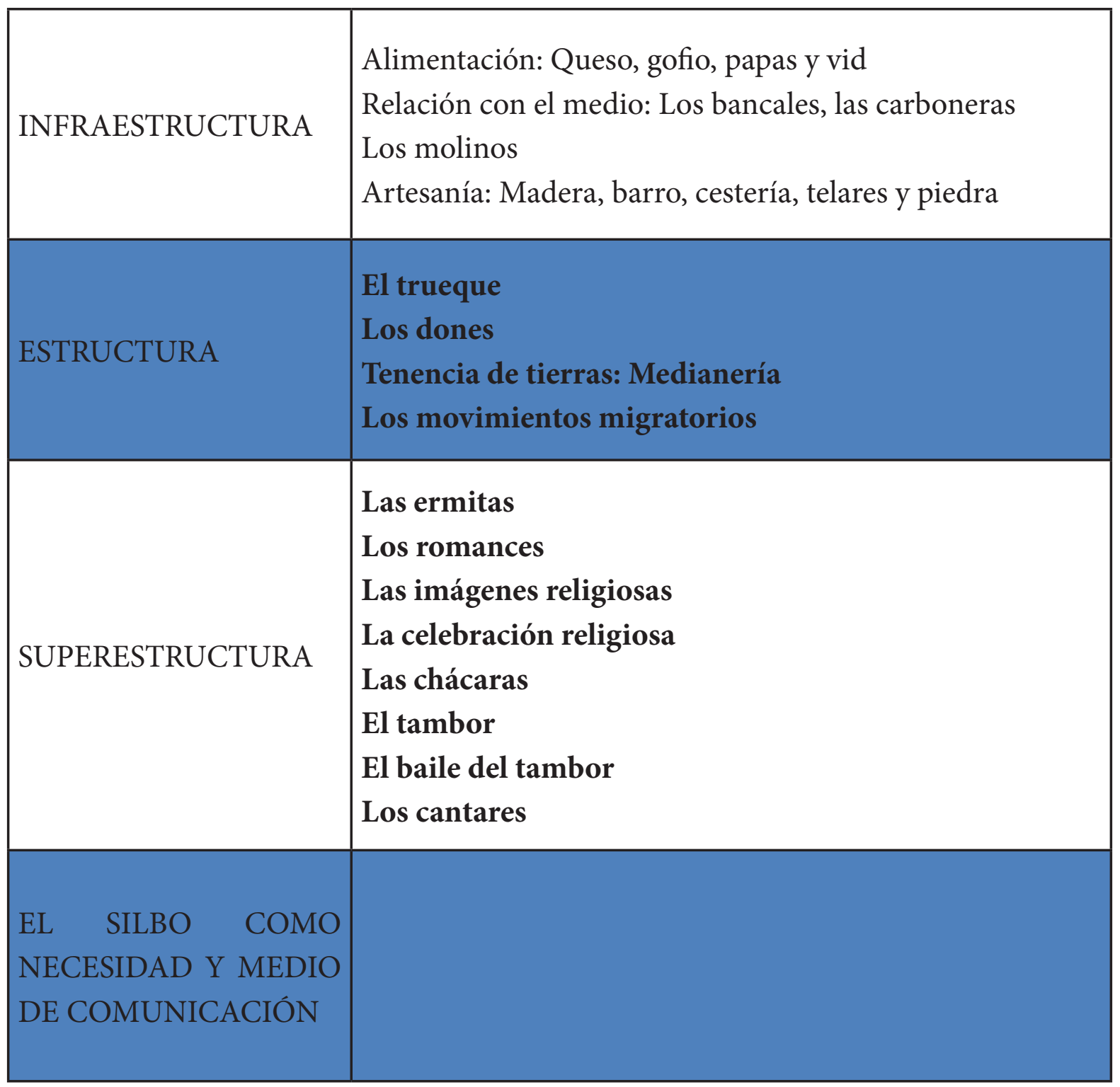

Fuente: Elaboración propia (García, 2016)

El silbo, como elemento cultural propio de la isla de La Gomera y declarado Patrimonio Cultural Inmaterial de la Humanidad por la Unesco en 2009 fue fruto del esfuerzo de la población, de la identificación de su importancia como elemento cultural propio y apoyado por las administraciones. Actualmente se enseña en los colegios, se realizan cursos y se difunde entre los visitantes de la isla.

Los procesos de construcción de la identidad en la Gomera y en sus espacios más rurales se han ido forjando en el tiempo y han sido mantenidos por la población, donde, 
a pesar de la dureza de las condiciones de vida, han sabido preservar esos elementos culturales como propios. Hoy constituyen un recurso importante para los turistas que visitan la isla y los proyectos de desarrollo y actuaciones llevadas a cabo por las diferentes administraciones intentan impulsar y conservar esos elementos desde diferentes tipos de actuaciones.

Numerosos planes de desarrollo se han puesto en marcha hasta hoy. La publicación del Ecoplan del año 1988 supuso un impulso para el concepto de "ecodesarrollo" con propuestas de actuaciones para fomentar un desarrollo sostenible desde los diferentes ámbitos. Posteriormente en el año 1996 se desarrollan parte de esas actuaciones a través del Plan de Actuación de medianías del Gobierno de Canarias y conjuntamente otras medidas desarrolladas por los Planes de Desarrollo Rural (PDR) y otras administraciones locales.

Actualmente el desarrollo económico, las mejoras de las comunicaciones y la importancia del turismo y sector servicios han propiciado un cambio favorable en su actividad económica. Su riqueza natural y cultural constituye un enorme reclamo para los turistas.

\section{LA ACTIVACIÓN DEL PATRIMONIO A TRAVÉS DE LOS PLANES DE DESARROLLO RURAL: GENERACIÓN DE RECURSOS E INTERRELACIONES CON EL SECTOR TURÍSTICO}

La Convención de la UNESCO en 1954 tuvo uno de sus grandes logros al definir el término de "bien cultural". En el largo camino de reconocimiento del patrimonio etnológico, la Convención sobre el Patrimonio Mundial Cultural y Natural en 1972 defiende un patrimonio conformado por testimonios del pasado que definen la memoria colectiva de un pueblo. En 1998 ya se crea una lista específica en la cual se habla de Obras Maestras del Patrimonio Oral e Inmaterial de la Humanidad (Fernández, 2006:46). Estas definiciones se van ampliando y se incluyen tradiciones orales, costumbres, fiestas, rituales, artes culinarias.

El Patrimonio cultural, por lo tanto, forma parte de una conciencia colectiva que incluye diversos significados referidos a viejos monumentos, prácticas culturales o conocimientos de nuestro entorno. Sin embargo, en este proceso, no todo se integra en lo que es patrimonio cultural sino que requiere de una selección del pasado y del presente que además aparezca como justificante de una identidad colectiva (Agudo, 2012).

El patrimonio local comienza también a ser entendido como un recurso que genera sinergias productivas en los territorios (Aguilar y Amaya, 2007) promoviéndose 
discursos de recuperación y revitalización de elementos culturales por diferentes agentes económicos, políticos y sociales. Desde esta perspectiva, la activación del patrimonio tiene sus efectos positivos en la generación de actividad y recursos económicos para la población y también para la protección y conservación de determinados elementos que en condiciones distintas desaparecerían.

El nuevo modelo de agricultura de la Unión Europea hizo que, a partir de los años 90 la política de desarrollo rural partiera de una concepción más integradora. El desarrollo rural con la reforma de 1999 (Agenda 2000) alcanza un apoyo financiero importante siendo un pilar fundamental de la Política Agraria Comunitaria (PAC).

La unión entre políticas económicas, preservación del medio ambiente y el impulso y participación de las comunidades locales en las zonas rurales da un cambio sustancial a los proyectos desarrollados posteriormente.

Este nuevo modelo de desarrollo rural es consecuencia de las continuas reflexiones sobre los problemas y necesidades reales del mundo rural. Estos espacios rurales cambian y adquieren nuevas funciones referentes a lo que la población demanda como parte de una sociedad mucho más globalizada. Este nuevo enfoque implica, entre otros aspectos, integrar lo endógeno pero también comprender la singularidad de los territorios (Navarro, 2007:157). Así, las iniciativas comunitarias para el desarrollo rural como Leader han entrado de forma progresiva en funcionamiento desde 1991 y están dirigidas a zonas rurales desfavorecidas, articulando diferentes principios y medidas que han conseguido una intervención mucho más eficaz. La finalidad de estas iniciativas era y es la potenciación de los grupos de acción local que tienen una gran capacidad para promover la participación de los agentes socioeconómicos y de la propia sociedad local.

En estas líneas de financiación, el último Programa de Desarrollo Rural (2014-2020) aprobado en agosto de 2015 está financiado por los Fondos FEADER y tiene como objetivo contribuir a un desarrollo del sector agrícola más equilibrado a nivel medioambiental y territorial.

El PDR cuenta con 19 líneas de actuación centradas en calidad de productos agrícolas y alimenticios, desarrollo de explotaciones agrícolas, servicios básicos y renovación de poblaciones en las zonas rurales entre otras. La medida en la cual se basan los proyectos analizados en este trabajo es la 19 de apoyo al desarrollo local (Leader). Sus objetivos se basan en la diversificación de la economía rural a través del apoyo a las PYMES y el emprendimiento.

Los casos analizadossecentran en diferentes proyectos públicosy privadossubvencionados por fondos Europeos en distintas convocatorias. Por un lado se analizan varios proyectos 
empresariales privados que tienen en la mayoría de los casos relación con elementos del patrimonio, y por otro lado públicos, centrados en dos centros de interpretación del patrimonio.

En la selección de los proyectos se tuvieron en cuenta principalmente los que actuaban sobre elementos identificativos de la población (García, 2016), la mayoría relacionados con la gastronomía y con productos locales, bien por su fabricación o por su relación entre sector turístico y patrimonio cultural.

La isla de La Gomera se constituye como un espacio donde el Patrimonio natural y cultural de la isla es enormemente atractivo para el sector turístico y es aquí donde la generación de recursos a través de estos proyectos empresariales tiene su vinculación con el turismo.

A partir de los ochenta se asiste a una multitud de nuevos turismos propiciado por las nuevas exigencias del mercado, competitividad, flexibilidad y segmentación; esa especificidad de la identidad cultural se convierte por tanto en un factor de atracción turística (Santana, 2003).

Al Igual que el patrimonio como fenómeno social, no podemos considerarlos aislado de los sistemas políticos y económicos ni de los sujetos implicados en ellos, la complejidad del turismo hay que entenderla en relación a los procesos sociales y culturales (NoguésPedregal, 2016).

Diferentes perspectivas desde la antropología o sociología han analizado el fenómeno turístico, en muchos casos desde las consecuencias negativas que producen en las comunidades receptoras (Nash, 1992; Turner y Ash, 1991; Greenwood, 1992). Los efectos culturales del contacto anfitrión-huésped, el concepto de búsqueda de la autenticidad o el concepto de post-turista (Cohen, 2005), el turismo como peregrinaje o la perspectiva dentro del sistema económico mundial (Urry, 2006; MacCannell, 2017) son algunos de los temas investigados.

Actualmente, y sin entrar en el debate sobre las relaciones entre anfitriones y turistas, o en los impactos negativos del turismo, es una realidad que este sector contribuye a generar recursos en los diferentes espacios aunque sus efectos den lugar a múltiples reflexiones.

\subsection{Proyectos empresariales y activación del Patrimonio: Un estudio de casos}

La relación entre elementos del patrimonio y proyectos empresariales en la isla de La Gomera tienen un importante apoyo en los Planes de Desarrollo Rural(PDR) financiados por los fondos Europeos FEADER y más concretamente en su medida 19 de apoyo al desarrollo local por las ayudas Leader. Los grupos de acción local como 
Aider en La Gomera gestionan estas iniciativas y aglutinan a más de 30 entidades con personalidad jurídica representativas del medio rural de la isla abarcando una plataforma de entidades, administraciones y agentes sociales. Alguno de los elementos más interesantes relacionados con sus líneas de trabajo se basa en la Carta Europea de Turismo Sostenible. Las empresas que se acreditan, trabajan con productos locales, con la artesanía y adquieren un compromiso con la sostenibilidad. Constituye un ejemplo de desarrollo endógeno, el cual se basa en los recursos específicos de cada zona.

Nos encontramos con pequeñas empresas, algunas de ellas especializadas en ciertos productos que a su vez son adquiridos por los turistas como producto local. El apoyo a estas iniciativas es un elemento indispensable de activación del patrimonio principalmente en los elementos considerados como parte del patrimonio local.

Estas pequeñas empresas abarcan diferentes actividades como la producción de miel de palma, la elaboración de queso de forma artesanal, la producción de gofio o galletas y un ejemplo de empresa turística que ofrece actividades en los cuales se mezclan e integran elementos etnográficos.

En el análisis realizado sobre la concesión de estas ayudas en los distintos años nos encontramos con varias medidas de subvenciones. La medida 312 de ayuda a la creación y desarrollo de microempresas y la 323 de conservación y mejora del patrimonio rural son las que han centrado este análisis. Posteriormente, en 2014, las medidas se dividen en proyectos productivos y no productivos.

Se analizaron diferentes proyectos subvencionados por fondos Leader en el periodo 20072014, escogiendo aquellos proyectos centrados en creación y mejora de empresas y los no productivos (Centros de interpretación). Se seleccionan los proyectos empresariales atendiendo a:

- La preservación de elementos identificativos de la población(gastronómicos, elaborados con productos locales y etnográficos relacionados con el turismo)

- Generación de actividad económica

- Variedad de productos

La metodología utilizada fueron entrevistas semiestructuradas y posteriormente se realiza las transcripción y análisis de las mismas estableciendo diferentes categorías de análisis. 
Las características de los promotores fueron $80 \%$ hombres y un $20 \%$ mujeres situados en un $70 \%$ entre los 30 y 40 años.

La valoración de las ayudas, los antecedentes familiares, las razones para el inicio de la actividad, la tradición como elementos del patrimonio, generación de empleo y expectativas de crecimiento fueron los factores analizados. La información obtenida hace referencia, en muchos casos a una tradición familiar, a recetas tradicionales o actividades turísticas centradas en la valoración del patrimonio.

Las ayudas son imprescindibles tanto en las fases de inicio como de consolidación y desarrollo. Estas ayudas no son en la mayoría de los casos determinantes como punto inicial de proyectos pero sí constituyen una mejora sustancial en determinadas fases, mejorando rendimientos y elaboración.

(...) las cuantías son importantes, si son un 75\%, un depósito ya te cuesta 3.000 euros (Bodega).

(...) "y luego compré la tostadora porque esa inyección de dinero te viene bien"(Molino de gofio).

Imagen 1: Bodega 1

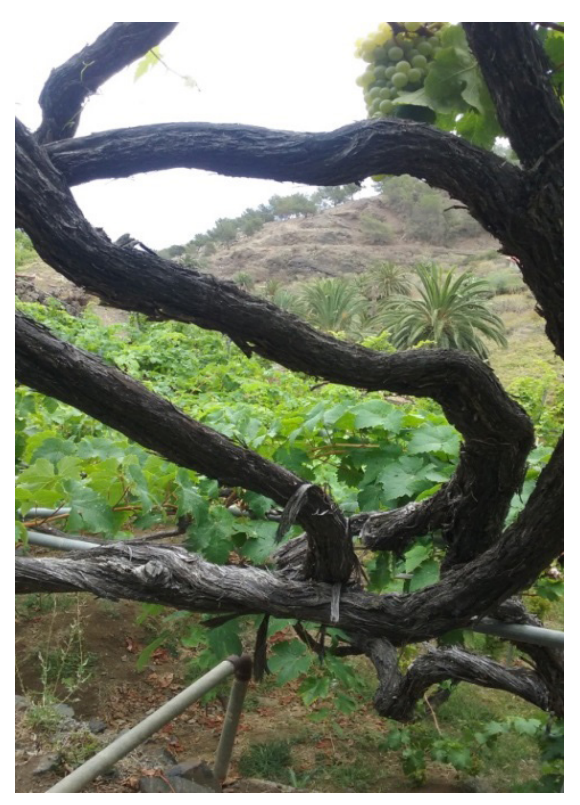

Fuente: Elaboración propia. Fotografía trabajo de campo (22/07/17) 
En diferentes proyectos nos encontramos promotores que tienen antecedentes familiares cercanos en la fabricación del producto y con un fuerte arraigo a su tierra; en algunos casos no se dedicaban exclusivamente a esa actividad y se produce una vuelta a su lugar de origen y en otros, la actividad desarrollada está relacionada con su formación o detección de necesidades.

“... dejo mi empresa en Tenerife, me pido una excedencia y me vengo a La Gomera seis días a la semana y me meto en un sitio de $20 \mathrm{~m} 2$ que es lo que tenía mi madre para fabricar las galletas. Empezamos con lo que sabía mi madre y empiezo yo a añadir formatos nuevos y empezamos con el almogrote, con una receta de mis abuelos" (Fábrica de galletas y otros productos).

"Yo si no es en La Gomera no, uno se adapta donde nació y yo me crié aqui" (Molino de gofio).

"Mi hermano estaba convencido de montar el molino de gofio y en octubre de 2007 empezamos a funcionar, yo me acuerdo el primer viaje a Tenerife que llevaba 170 kilos de gofio y ahora llevamos 3.000 y 4.000 kilos" (Molino de Gofio).

Las razones para el desarrollo de estas actividades varían entre una actividad que ya se realizaba anteriormente sea de forma continua o como complemento de otras actividades, la detección de un nicho de mercado elaborado con productos locales o por necesidad. En la mayoría de estos casos la revalorización del producto local y la búsqueda de mercado dentro y fuera de la isla mezclado con antecedentes familiares constituyen parte de estos inicios.

"Siempre nos hemos criado con gofio. Mi padre fue a Venezuela y se llevó 8 kilos de gofio, fue lo único que se llevó" (Molino de Gofio).

En el caso del proyecto empresarial de cosmética surge porque eran productores de miel, por la detección de un nicho de mercado y para dar un valor añadido a este producto. Empiezan a producir cosmética que, posteriormente, tendrá la certificación de ecológica. Lo innovador de este producto son los ingredientes que se basan en aromas y productos locales, trabajan con plantas autóctonas. Actualmente toda la producción de miel va para la cosmética (Entrevista no grabada). 


\section{Imagen 2. Empresa de cosmética natural}

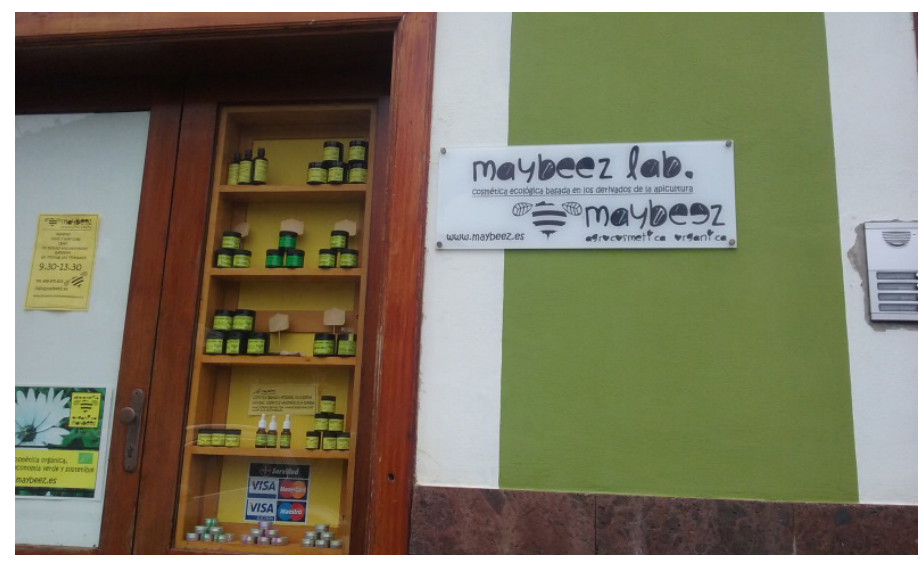

Fuente: Elaboración propia. Fotografía trabajo de campo (21/07/17)

En relación a las razones de inicio de actividad una de las bodegas comenta:

"La afición por la viña viene de mi abuelo. Aquí tu sabes en la época nuestra fue muy dura. Yo me fui a Venezuela con 16 años(...) la finca la tenía mi padre a medias(hace referencia a que eran medianeros). Antes del 2000 empecé a embotellar. Las primeras me fui a Valle Gran Rey con mi hija, entonces me trataban de loco, para que embotellas si viene de la península y viene barato. Pero luego la gente ya vio que estos vinos eran de aquí y ya me empezaron a llamar, primero blancos y luego tintos" (Propietario de bodega).

Actualmente los vinos de esta bodega se encuentran y son adquiridos en todos los supermercados de la isla con su denominación de origen. Otras bodegas distribuyen sus vinos directamente a restaurantes y es más difícil encontrarlos. En cualquier caso el vino con la identificación de su denominación de origen de la isla de La Gomera constituye un impulso importante a los productos locales. Estas bodegas conservan una gran tradición con viñas antiguas adquiridas por sus familiares y un contexto de vendimia cargado de costumbres y cultura local.

En el mantenimiento de las tradiciones y productos locales encontramos un molino de gofio. El gofio como elemento básico de la alimentación de la población guarda en 
su proceso una gran cantidad de historias sobre su elaboración, sobre las dificultades en época de hambre para conseguir el millo, costumbres y rituales, reuniones de la población, intercambios y un enriquecedor contexto cultural. En el caso de este emprendedor continuó con la labor de su hermano, y es un producto local que ha sido premiado en los años anteriores y en el 2018 como el mejor Gofio de Canarias. Estos premios dan un impulso y reconocimiento a los elementos gastronómicos locales. Muchos restaurantes y otros establecimientos utilizan este gofio para la elaboración de platos típicos identificando este molino y la calidad de su gofio.

\begin{abstract}
"Mi abuela paterna y materna tenían molinos. (...) los molinos eran por herencia y el que tenía un molino era un privilegiado (...) allí practicaban los pies de romances iba gente y familias y se quedaban toda la noche. Nosotros siempre nos hemos cridado con gofio" (Propietario molino de gofio).
\end{abstract}

Otro de los casos analizados es una fábrica de producción de galletas y distintos productos locales como el almogrote o la miel de palma. En este caso, las recetas tradicionales de su familia han servido para retomar la actividad, provocar una vuelta a la isla y generar empleo y actividad económica en el municipio de Alojera. Actualmente este emprendedor quiere crear una línea gourmet y su expansión ha llevado estos productos tradicionales a otras islas y a los grandes centros comerciales siempre con la denominación de "productos de La Gomera”. En todos los supermercados de la isla se encuentra parte de esta producción.

"La historia de empieza en realidad hace 35, 40 años. Mi madre empezó a aprender el oficio de repostería en una panadería del pueblo (...) hizo un horno pequeñito y hacía sus galletas" (Empresa de galletas y productos tradicionales).

Estos productos gastronómicos locales llevan la Marca "Alimentos de La Gomera" como señal de identidad geográfica y distintivo de calidad cuya marca fue creada por el Cabildo Insular de la Gomera para proteger e identificar estos productos artesanos contribuyendo a su valorización y conservación. Los vinos también tienen la denominación de origen de La Gomera y tienen su Consejo Regulador en el municipio de Vallehermoso.

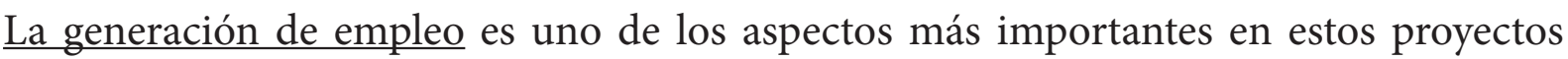
empresariales. Este factor constituye un elemento imprescindible para el mantenimiento de la población en determinadas zonas o en relación a la vuelta a sus lugares de origen. 
Las iniciativas analizadas, al ser pequeñas empresas, generan un tímido incremento de puestos de trabajo aunque la mayoría tienen previsión de crecimiento. En las bodegas el empleo se produce principalmente en la época de vendimia.

"Mi familia, el chico que trabaja aquí, el distribuidor de La Gomera, el de Tenerife y mi sobrino en época de verano" (Molino de gofio).

"La gente que trabaja aqui es toda del pueblo, hemos pasado de dos personas a doce y la idea es tener más" (Empresa de galletas y diversos productos).

En el caso de la empresa de turismo, nos encontramos con una integración del turismo sostenible que mezcla, naturaleza, historia y elementos culturales con un objetivo claro de revalorizar y poner en valor el patrimonio de La Gomera. Su actividad en época de verano se centra principalmente en tema de campamentos y población más local y en invierno turismo extranjero. Tienen recorridos por el Parque Nacional de Garajonay, visitas a la bodega escondida donde realizan degustación del vino, visitas a queserías entre otras actividades. La filosofía de la empresa es generar economía dentro de la población local, para ello los turistas se alojan en diferentes municipios, se organizan comidas en diferentes establecimientos y en definitiva intentan diversificar. Esta es parte de la filosofía de la Carta Europea de Turismo Sostenible a la cual están adheridas numerosas empresas y establecimientos.

"Es una empresa que se crea principalmente para senderismo, pero es mucho más, todo lo que trabajamos está enfocado en la revalorización del patrimonio que tiene la isla, ya sea a nivel etnográfico, histórico, artesanía y demás" (Empresa de turismo sostenible).

Estos proyectos difunden el patrimonio local, generan actividad económica y un tímido empleo, mantienen a la población y conservan antiguas tradiciones en la elaboración de sus productos. 
Tabla 2. Proyectos empresariales seleccionados y subvencionados con Fondos Leader.

\begin{tabular}{|c|c|c|c|c|}
\hline $\begin{array}{c}\text { Empresa } \\
\text { Fecha entrevista }\end{array}$ & Sexo/Edad & Productos & $\begin{array}{l}\text { Empleo actual/ } \\
\text { Expectativas de } \\
\text { crear más puestos }\end{array}$ & $\begin{array}{l}\text { Años de } \\
\text { funcionamiento }\end{array}$ \\
\hline $\begin{array}{l}\text { Molino de Gofio } \\
\text { 18/07/17 }\end{array}$ & H. 30-40 años & $\begin{array}{l}\text { Elaboración y } \\
\text { envasado de } \\
\text { gofio }\end{array}$ & 4. Sí & 10 años \\
\hline $\begin{array}{l}\text { Empresa de } \\
\text { galletas y diversos } \\
\text { productos } \\
13 / 07 / 17\end{array}$ & H. 30-40 años & $\begin{array}{l}\text { Elaboración } \\
\text { de galletas, } \\
\text { almogrote, } \\
\text { mojos, } \\
\text { mermeladas y } \\
\text { miel de palma }\end{array}$ & 12. Sí & 11 años \\
\hline $\begin{array}{l}\text { Miel de Palma. } \\
\text { 20/07/17 }\end{array}$ & H. 30-40 años & Miel de Palma & 4.Sí & 3 años \\
\hline $\begin{array}{l}\text { Productos } \\
\text { turísticos- } \\
\text { etnográficos. } \\
21 / 07 / 17 \\
\end{array}$ & M.30-40 años & $\begin{array}{l}\text { Productos } \\
\text { turísticos. }\end{array}$ & 2. (1 Las Loceras) & 6 años \\
\hline $\begin{array}{l}\text { Cosmética natural } \\
21 / 07 / 17\end{array}$ & M.30-40 años & $\begin{array}{l}\text { Cosmética } \\
\text { natural } \\
\text { elaborada con } \\
\text { producción } \\
\text { local }\end{array}$ & 2. Sí & 4-5 años \\
\hline $\begin{array}{l}\text { Bodega } 1 \\
22 / 07 / 17\end{array}$ & $\mathrm{H} /+60$ & $\begin{array}{l}\text { Producción y } \\
\text { envasado de } \\
\text { vinos }\end{array}$ & En vendimia & +15 años \\
\hline $\begin{array}{l}\text { Bodega } 2 \\
24 / 07 / 17\end{array}$ & $\mathrm{H} /+60$ & $\begin{array}{l}\text { Producción y } \\
\text { envasados de } \\
\text { vinos }\end{array}$ & En vendimia & +15 años \\
\hline $\begin{array}{l}\text { Quesería } 1 \\
24 / 07 / 17\end{array}$ & $\begin{array}{l}\text { H y } \mathrm{M} / 30-40 \\
\text { años }\end{array}$ & $\begin{array}{l}\text { Producción de } \\
\text { quesos. Rebaño } \\
\text { propio }\end{array}$ & $2-$ & $\begin{array}{l}+30 \text { años/ } \\
\text { arrendado hace } \\
6 \text { meses }\end{array}$ \\
\hline $\begin{array}{l}\text { Quesería } 2 \\
25 / 07 / 17\end{array}$ & H.+ 60 & $\begin{array}{l}\text { Producción de } \\
\text { queso }\end{array}$ & 2 (padre e hijo) & +20 años \\
\hline
\end{tabular}

Fuente: Elaboración propia 
La inserción de poblaciones locales en circuitos mercantiles, así como el surgimiento de empresas que lo hacen efectivo es un claro ejemplo de alguno de estos proyectos.

\subsection{Los Centros de Interpretación del Patrimonio: Las Loceras y La Casa de la Miel de Palma}

La artesanía en la isla de La Gomera tiene una gran importancia por el valor que representa a través de su historia. Numerosos artesanos viven en las zonas altas de la isla, como se pudo comprobar en el trabajo etnográfico sobre las medianías (García, 2016). Conocimientos tradicionales en su elaboración que en muchos casos han pasado a través de generaciones. En la actualidad, la administración intenta que estas actividades no se pierdan a través de diferentes iniciativas.

En el caso de los artesanos, nos encontramos con población con una edad avanzada y cuyos conocimientos les vienen por tradición familiar. En pocas ocasiones se observa población joven en las entrevistas realizadas en 2014 y 2017. La artesanía constituía en épocas de dificultades económicas un recurso para intercambiar productos o venderlos. Estos productos artesanos tenían distintas funciones relacionadas con los trabajo en el campo, decorativos, para el folclore, como utensilios de cocina, para la ganadería etc.

(...) "yo desde los 18 años empecé en el telar porque mi padre murió y como veía que no había salida para las mujeres... La artesanía no paga nunca este trabajo (...) el telar era de mi bisabuela y se lo dio a mi abuela" (Artesana, A5).

"La artesanía no es que se pueda vivir de esto pero es una ayuda (..) yo me acuerdo de mandar a mi sobrina con lo que habia hecho y me traía, 20, 20.000 pesetas. Una vez lo llevé allá... a Pinolere y lo vendí todo; una vez que nos invitó el Cabildo e íbamos con gastos pagos, entonces me invitó y fui con mi marido, tres días estuvimos allá" (Artesana A1).

En referencia a la importancia de la artesanía y las subvenciones de Fondos Europeos, las iniciativas no productivas como los diferentes centros de interpretación constituyen, cuando se gestionan y se difunden de forma eficiente un elemento importante del conjunto de actuaciones para preservar el patrimonio. El Centro de interpretación de la miel de palma (Casa de la miel de palma) y un segundo centro, relacionado más directamente con la artesanía, Las Loceras, han sido subvencionados por estos Planes de Desarrollo Rural. Ambos elementos, la miel de palma y la cerámica son claramente identificativos de la población.

La miel de palma se elabora a través del guarapo que se extrae de las palmeras. Nos 
encontramos con un elemento gastronómico muy importante para la población el cual es rastreado en los numerosos documentos históricos. La forma de trabajar las palmeras es totalmente tradicional, algo más industrial en la cocción a través de quemadores pero no en su extracción. Es un producto típico de la isla y muy valorado en la gastronomía isleña. Actualmente existen numerosas empresas que producen esta miel, ahora con otra denominación (sirope, extracto) por obligación de las autoridades Europeas. La zona de Tazo es muy valorada por la calidad de su miel, Cubaba, Royal Palm, La Encantadora, son algunas de las empresas que trabajan las palmeras, elaboran y embotellan la miel.

El centro de interpretación de la miel de Palma, ubicado en el municipio de Alojera y subvencionado por Fondos Europeos es un espacio en el cual se explica todo el proceso de elaboración de la miel pero también en forma de exposición, los usos que de la palmera se daba. La Palma es un elemento que se ha utilizado en la isla con múltiples funciones, desde escobas, barcos para los niños, esteras realizadas por las artesanas, colmenas con el tronco, miel del guarapo, alimento para los animales etc.

Este centro también realiza numerosas actividades con los niños a través de talleres y una artesana imparte, en algunas ocasiones, cursos para hacer esteras. Desde una perspectiva crítica y después de la visita al centro falta contenido en referencia a la producción y elaboración de la miel de palma al igual que audiovisuales que den más imagen a una actividad tan importante en la isla.

En el caso de la cerámica, el Centro de Las Loceras se encuentra ubicado en El Cercado, donde la actividad de la alfarería ha sido muy importante, actualmente este espacio es cada vez más reducido. Nos encontramos con tres espacios individuales de venta de cerámica y que antes de 2017 eran cinco, a poca distancia se encuentra el Centro de interpretación Las Loceras. Las artesanas no hacen especial referencia al centro y sí se comenta la poca visibilidad que tiene su actividad, por ejemplo, dentro de los circuitos turísticos de autobuses turísticos que pasan por la zona.

Existe poco relevo generacional aunque en el caso de dos de ellas, sus hijas sí han seguido la trayectoria de su madre. En otro de estos espacios artesanos individuales un joven continúa la labor de la artesana dueña de ese espacio.

Nos encontramos con piezas de todo tipo, positivamente en alguno de estos espacios con fichas sobre el tamaño, características y funcionalidad de cada pieza artesana; esto ha sido gracias a un trabajo realizado desde el grupo de acción local (Aider La Gomera) para poder identificar claramente cómo era cada una de esas piezas originalmente.

Actualmente existen piezas tradicionales y en algunos casos se mezclan con piezas nuevas o menores de tamaño. La explicación normalmente por parte de los artesanos en las piezas más pequeñas es funcional y económica, los turistas no pueden llevarse piezas 
tan grandes. En cuanto a la elaboración hacen referencia a la dificultad del amasado del barro por su dureza. En algún caso se introducen modificaciones que rompen de alguna manera con la elaboración tradicional. Normalmente el alisado de la pieza siempre se realiza con piedra y en alguno de esto espacios artesanos se está utilizando una pieza de plástico que le da un alisado mucho más perfecto en contraste con la imagen tradicional de las piezas.

La tradición de estás alfareras viene de madres, abuelas o tías como comenta una de las alfareras con casi 70 años. Estas piezas tienen su funcionalidad: vasijas para ordeño, para las papas y el mojo, para hacer bizcochos etc. Estas piezas iban a venderlas a otras zonas de la isla caminando grandes distancias o también las utilizaban para los intercambios o el trueque por alimentos.

Estos centros, al igual que el centro de interpretación de miel de palma tienen numerosas visitas y actividades con los colegios de los diferentes municipios. En el caso de Las Loceras este centro abre sus puertas en 2007 pero es cerrado y, posteriormente, vuelve a su actividad años después. En concreto este centro depende del Ayuntamiento y se da la concesión por determinado tiempo a alguna empresa. Este espacio de información sobre el proceso de elaboración de las piezas de barro tiene un número bajo de visitantes en épocas de verano, ya que es un visitante más local y en invierno tienen más volumen de turistas, sobre todo extranjeros, alemanes y suizos, entre otros. En los meses de enero pueden tener como es el caso de 2017, 458 visitantes y posteriormente, a partir de junio, van disminuyendo.

Nos encontramos con un centro que ha tenido una continuidad intermitente, en una zona muy importante de alfarería, única en toda la isla, con artesanas todavía realizando su actividad. El contenido y las explicaciones sobre el proceso de elaboración serían mejorables si tuvieran, por ejemplo, audiovisual o una mayor cercanía con las artesanas. Cada pieza puede verse de forma real y el contexto social y económico es el inicio de la información que se da del centro, haciendo referencias históricas a la alfarería en la Gomera y en concreto al Cercado.

Estos centros de interpretación del patrimonio tienen una funcionalidad real e importante de cara al turismo pero otros, en previsión o incluso abiertos pero sin apenas uso, exponen las dificultades que tienen las administraciones en el mantenimiento de estos proyectos turísticos patrimoniales. Tal y como comenta Prats (2003), los conflictos para el mantenimiento de estos centros son evidentes y principalmente cuando, en algunos casos, se justifica su existencia con la generalización de un turismo escolar que en muchos casos maquillan el número de visitantes.

La funcionalidad del centro está justificada como difusor del patrimonio local, tanto en actividades con colegios como con turistas pero tiene que tener una proyección mucho 
mayor. "En términos de supervivencia política, podríamos decir que recuperar y conservar el patrimonio es siempre una actuación extraordinariamente eficaz por el elevado nivel de consenso social que suscita, en cambio activar ese mismo patrimonio de una forma más permanente constituye una operación mucho más arriesgada"(Prats, 2003: 129).

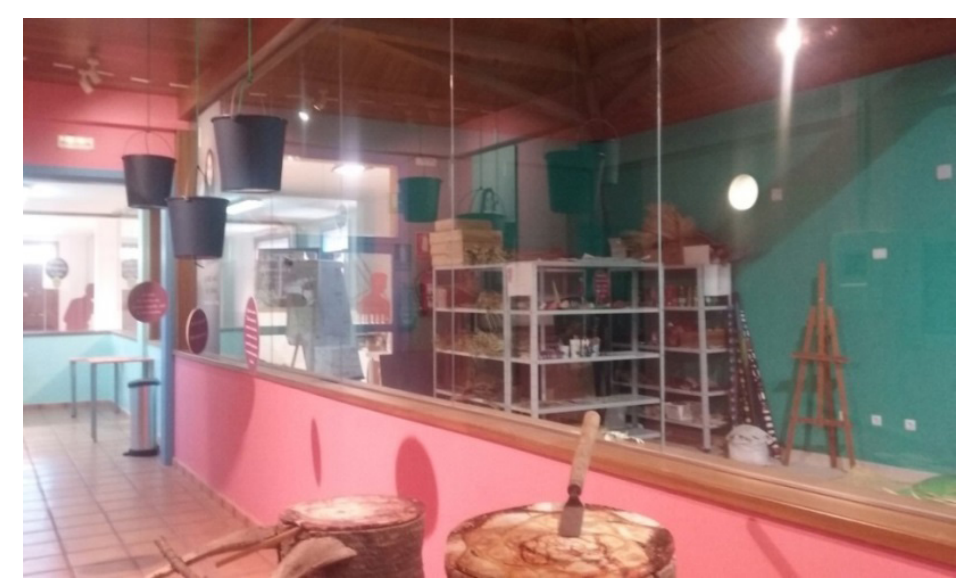

Fuente: Elaboración propia. Fotografía trabajo de campo (12/07/17)

\subsection{Relaciones con el sector turístico}

El turismo es visto en algunos casos como una vía hacia la dependencia, consolidando las relaciones de dominación (Turner y Ash, 1991) o como una forma de imperialismo que puede servir para exacerbar las fisuras sociales ya existentes o hacer aparecer otras (Nash, 1992:90). También otros autores se han centrado inicialmente en cómo investigar el sistema turístico desde la antropología (Santana, 1997), en el análisis sobre las principales tendencias del turismo contemporáneo, analizando el concepto de post-turista (Cohen, 2005) o en los conflictos entre población, autoridades y turistas en relación a la visita a monumentos (Odermatt, 2011).

Sin embargo, algunas perspectivas de análisis exponen el análisis de casos en los cuales el turismo estimula la identidad y preserva oficios y tradiciones (Boissevain, 1991: 406).

La diversificación de las tipologías turísticas requiere un análisis en profundidad sobre, por ejemplo, las alternativas al turismo de masas, y también un análisis sobre los espacios en los cuales se ubican, comprendiendo los procesos sociales y culturales que suceden en su entorno (Nogués, 2016:39). Estas diferencias marcan lo que es un turismo sin control y un turismo más sostenible respetuoso con la comunidad y con su medio en general.

El turismo no es un fenómeno monolítico, es una industria que funciona con una gran diversidad y que por tanto hemos de distinguir entre distintos tipos de turistas (Greenwood 1992:258). En este punto se requiere que las administraciones competentes 
en esta materia regulen, organicen y planifiquen actuaciones que incidan no solamente en el turista sino en el bienestar de la comunidad donde se insertan.

El turismo, por tanto, como fenómeno en el que concurren múltiples factores y variables también puede ser analizado e interrelacionado con los efectos que tienen los planes de desarrollo rural sobre la activación del patrimonio.

La isla de La Gomera constituye un espacio natural y cultural que por sus características atrae a una tipología de turistas que buscan además de playa, vivir experiencias auténticas (MacCannell, 2017: 133). En este aspecto la generación de actividad económica que hemos visto en los diferentes proyectos tiene un punto en común y es la utilización de elementos culturales propios de la isla. En otros casos, esta generación de actividad da lugar en la isla a incrementar los recursos y actividades que son ofrecidas y consumidas por los turistas.

El impulso de estas iniciativas tiene como efectos:

- La generación de actividad económica que en muchos casos está directamente relacionada con el patrimonio y turismo como es el caso de la empresa Ymaguara de rutas etnográficas por la isla.

- Un incremento de centros de interpretación en donde se difunde la cultura de la isla.

- Proyectos empresariales que inciden en elementos gastronómicos identificativos de la isla (gofio, queso, miel de palma).

- Proyectos empresariales elaborados con productos locales (cosmética natural con miel de la zona).

- Proyectos empresariales que, en general, realizan actividades que incrementan en muchos casos los servicios que se ofrecen a los turistas. Es el caso de algunos proyectos que ofrecen visitas en burro (subvención en 2009) o a caballo.

En definitiva, el Patrimonio provoca tanto en entidades públicas como privadas un intento de recuperación y revitalización de elementos culturales en muchos orientada a una demanda cada vez más grande y especializada de la actividad turística.

Este incremento cada vez mayor de actividad dirigida al sector turístico lleva conjuntamente una reflexión sobre la mercantilización de la cultura y requiere un análisis y trabajo de campo en profundidad. Los proyectos analizados difunden sus tradiciones a través de sus visitas o por ejemplo etiquetado del producto. Sin embargo, existen otros ejemplos cuya mercantilización es frecuente y generan dudas acerca de cómo se vende ese producto y de si conlleva en sí mismo parte de la historia de su producción o si se está dando una imagen no real del mismo. 
En esa línea, y para poder clasificar este tipo de actividades resulta muy clara la distinción que realiza Prats (1997).

En la relación entre empresas turísticas y recursos patrimoniales hace referencia a tres tipos de asociación (Prats, 1997:44): 1. Empresas públicas y privadas que venden el patrimonio natural y cultural 2. Empresas de hostelería y restauración que utilizan el patrimonio como reclamo y 3. Empresas dedicadas a alguna actividad o recurso turístico no patrimonial y que normalmente ignoran el patrimonio.

En esta primera relación podemos ubicar las iniciativas empresariales y centros de interpretación subvencionados por los Planes de Desarrollo Rural analizados anteriormente.

Por otro lado, y volviendo a los proyectos empresariales, el análisis de proyectos que han fracasado en su actividad pueden ampliar líneas de trabajo que generen propuestas de mejora en el asesoramiento a estos emprendedores.

El segundo tipo de asociación constituye una línea de trabajo interesante para profundizar a través de un trabajo de campo intensivo y se basa en conocer la imagen e información que se difunde de los elementos culturales de la isla a través de estos establecimientos. Un claro ejemplo lo tenemos en los diferentes restaurantes que hacen demostraciones del silbo. Las tiendas de souvenir serían también un excelente laboratorio de análisis para observar y conocer en estado puro esa mercantilización de la cultura.

En referencia a la tercera asociación nos encontramos proyectos sobre los cuales no se ha realizado trabajo de campo por no estar directamente relacionados con el patrimonio pero que sí generan una actividad y servicios en general, tanto para la población, como para los turistas.

Por último, y en forma de reflexión, destacar la importancia de proteger, investigar y difundir la artesanía de la isla puesto que es y ha sido un elemento identificativo de la población. Las diferentes acciones de promoción por parte de las administraciones, Cabildo y Ayuntamientos impulsan, a través de las Ferias de Artesanía entre otras medidas, la exposición de estos productos fabricados por los artesanos. No obstante, la avanzada edad de algunos de ellos y la dificultad de relevo generacional hacen imprescindible un análisis en profundidad de las medidas que se están llevando a cabo y de sus efectos. La percepción y conocimiento que tiene el turista del valor de estos productos sería otra interesante línea de investigación sobre la cual profundizar.

\section{CONCLUSIONES.}

Las nuevas políticas de desarrollo rural aparecen con una visión muchos más integradora acorde a la diversidad de sociedades rurales en términos de composición 
social, estructura económica, historia y cultura. Los diferentes proyectos empresariales analizados constituyen un ejemplo de activación del patrimonio y de generación de empleo a través de los planes de desarrollo rural. Estos recursos económicos generados a través de los Fondos Europeos y gestionados por los Grupos de Acción Local constituyen un importante impulso no solamente para los emprendedores locales que inician su actividad, sino para la mejora de las empresas que se encuentran actualmente en funcionamiento.

Las características de estos proyectos demuestran un profundo arraigo a la isla y un mantenimiento en muchos casos de tradiciones y costumbres familiares. En otros casos, estos proyectos son recursos que se generan directa o indirectamente para los turistas que visitan la isla, ya sea directamente a través de visitas a bodegas, rutas etnográficas o de la simple venta de productos gastronómicos que se adquieren en un supermercado con la distinción de producto de La Gomera. Las grandes dificultades de estos proyectos en muchos casos vienen por la necesidad de ampliación de espacio, económicas para mejorar su producción en maquinarias, la escasez de materia prima, sea la miel, cereal o leche o las dificultades propias del espacio insular. Es necesario, por tanto, incidir en estas limitaciones y dificultades, para, en la medida de lo posible, facilitar la puesta en marcha y continuidad de sus actividades.

Por otro lado, es necesaria una visión crítica de la proliferación de los Centros de Interpretación, aun reconociendo la gran importancia que tienen para la difusión del patrimonio. En muchos casos, estos espacios identificativos de la cultura de la isla requieren un esfuerzo mayor de gestión en cuanto a la realización de actividades, difusión y mejoras continuas, existiendo centros que se han cerrado o no han llegado a funcionar.

Para avanzar en este desarrollo es necesario diseñar políticas económicas adecuadas que protejan el patrimonio y donde la implicación y participación local de todos los agentes sociales, económicos y políticos sea imprescindible.

Un turismo de masas puede llevar a la pérdida de privacidad y afectar en general a la comunidad local desde diferentes ámbitos. Un turismo responsable, sostenible y planificado puede llevar mejoras a las comunidades, empezando por un mantenimiento de la población a través de la generación de actividad económica y de sus elementos de identidad. Sin embargo es necesario un control de las políticas y actuaciones que se llevan a cabo sobre el sector turístico y una evaluación posterior de sus efectos. La investigación etnográfica puede aportar conocimientos al estudio de la mercantilización de la cultura $\mathrm{y}$ al intento de equilibrar las distintas actuaciones desde las administraciones con las necesidades y el bienestar de la población local. 


\section{REFERENCIAS BIBLIOGRÁFICAS}

Álvarez, Juan (1960) "Primera conquista y cristianización de La Gomera". Anuario de Estudios Atlánticos 6. Madrid-Las Palmas: Patronato de La Casa de Colón.

Agudo, Juan. (2012) "Patrimonio etnológico y juego de identidades", Revista Andaluza de Antropología 2, pp. 3-24.

Aguilar, Encarnación, Merino Dolores y Migens Mercedes (2003) "Cultura, políticas de desarrollo y turismo rural en el ámbito de la Globalización”. Horizontes Antropológicos 20 (9), pp. 161-183.

Aguilar, Encarnación y Amaya, Santiago (2007) "El patrimonio cultural como activo del desarrollo rural”. En J. Sanz Cañada (ed.) El Futuro del Mundo Rural. Madrid: Editorial Síntesis, pp.103-121.

Aguilar, Encarnación. y Pérez, A. (2013) "Aportaciones al análisis comparativo entre modelos de desarrollo rural en Europa". Gazeta de Antropología, 29(2), artículo 02.

Alburquerque Llorens, F. (2007) "Desarrollo rural, desarrollo local y desarrollo sostenible". En Sanz Cañada, J. (ed.) El Futuro del Mundo Rural. Madrid: Editorial Síntesis, pp. 25-71. Beck, Ulrich (2006) [1986] La sociedad de riesgo. Hacia una nueva modernidad. Barcelona: Paidós.

Berger, L. Peter y Luckmann T (2011) [1967] La Construcción social de la realidad. Buenos Aires: Amorrortu Editores.

Boissevain, Jeremy (ed.) (2011) [1996] Lidiar con turistas. Reacciones europeas al turismo en masa. Barcelona. Ediciones Bellaterra.

Bethencourt, Juan (1881). "El silbo articulado en La Gomera". Revista de Canarias 21 Tomo III.

Briones, Rafael (1991). "Identidad y poder en las fiestas patronales de los Guájares". Gazeta de Antropología 8, artículo 07.

Burriel L De Orueta, E. (1982). Canarias: Población y agricultura en una sociedad dependiente. Barcelona: Oikos Tau.

Cabildo Insular de La Gomera. Acciones del Área de turismo. Enero, febrero y marzo 2018 [Consultado el 5 de mayo de 2018].

Camarero, Luis. (2009). La Población Rural de España. De los desequilibrios a la sostenibilidad social. Colección de Estudios Sociales, 27. Barcelona: Fundación La Caixa. Cohen, Eric (2005). "Principales tendencias en el turismo contemporáneo". Política y Sociedad, 42(1), pp. 11-24.

Comas, Dolors. (1988). Antropología Económica. Barcelona: Editorial Ariel. 
De Castro, Juan (2010) (edición y estudio crítico Gloria Díaz Padilla). La isla de La Gomera en la actualidad. Año 1856. Santa Cruz de Tenerife: Ediciones Idea.

De Kadt, Emanuel (1991) [1979]. Turismo: ¿Pasaporte al desarrollo? Madrid: Endymion.

Del Mármol, C.,Frigole,J.y Narotzky, S. (eds.) (2010). Los Lindes del Patrimonio. Consumo y valores del pasado. Barcelona: Icaria.

Díaz, Gloria y Rodríguez, José Miguel (1990). El Señorío en las Canarias Occidentales. La Gomera y el Hierro hasta 1700.Santa Cruz de Tenerife: Cabildo Insular del Hierro y Cabildo Insular de Tenerife.

Fernández, Esther (2006) "Del tesoro ilustrado a recurso turístico: el cambiante significado del patrimonio cultural". Pasos. Revista de Turismo y Patrimonio Cultural 4(1), pp.1-12.

Gama, Marissa Gabriela y Fávila, Hector (2018). "Una aproximación a la experiencia turística desde la Antropología del Turismo: una mirada mutua al encuentro entre turistas y locales". Pasos. Revista de Turismo y Patrimonio Cultural 6(1), pp.197-211.

García, Patricia (2016). La construcción de la identidad cultural y los procesos de cambio social en las medianías de la isla de La Gomera. (Tesis doctoral no publicada). Universidad de Granada.

García, Patricia (2015) "Una aproximación etnográfica a las medianías de la isla de La Gomera: Cultura, economía y movimientos migratorios”. Revista de Humanidades, 26, pp.1-20.

García, José Luis (1998). "De la cultura como patrimonio al patrimonio cultural”. Política y Sociedad, 27, pp.9-20.

Geertz, Clifford (2006) [1973]. La interpretación de las culturas. Barcelona: Gedisa Editorial.

Gobierno de Canarias (1996). Plan de Actuación especial en las medianías de la Gomera. Gobierno de Canarias. Consejería de Agricultura, Ganadería, Pesca y Aguas. Plan de Desarrollo Rural de Canarias (PDR) (2014-2020).

Godelier, Maurice (2015) [1974]. Economía, fetichismo y religión en las sociedades primitivas. Madrid: Siglo XXI.

Godelier, Maurice (1987). “Los procesos de transición. Estudios de casos antropológicos”. Revista Internacional de Ciencias Sociales XX 114, pp.5-16.

Grenwood, Davydd J. (1992) [1977] "La cultura al peso: perspectiva antropológica del turismo en tanto proceso de mercantilización cultural”. En Valene L. Smith (coord.) Anfitriones e invitados. Antropología del Turismo. Madrid: Endymion, pp. 257-279 
Greenwood, Davydd J. (2001) “El estudio del cambio como camino real a la teoría”. En Centro de investigaciones sociológicas Estructura y cambio social. Libro Homenaje a Salustiano del Campo. Madrid: CIS. pp. 73-85).

Harris, Marvin (1982) El materialismo cultural. Madrid: Alianza editorial.

Hernández, Javier (2015) “Turismo de base local en la Globalización”. Revista Andaluza de Antropología 8, pp.1-18.

Hobsbawm, Eric (2012) La invención de la tradición. Barcelona: Crítica S.L.

Ward, N., Murdoch, J. y Lowe, P. (1997) "Redes en el desarrollo rural: Más allá de los modelos exógenos y endógenos”. Agricultura y Sociedad 82, pp.13-43.

MacCannell, Dean (2017) [1976]. El turista. Una teoría de la clase ociosa. España: Editorial Melusina.

Marsden, T.; Murdoch, J.; ,Lowe, P.; Munton, R. y Flynn, A. (1993). Constructing the Countryside. London: UCL Press.

Mauss, Marcel (2009) [2007]. Ensayo sobre el don. Buenos Aires: Katz Editores.

Ministerio de Obras Públicas y Urbanismo (1988) Ecoplan para la isla de La Gomera.

Mormont, Marc (1990) "Who is Rural? or, how to be rural: Towards a Sociology of the Rural”. En T. Marsden, P.Lowe y S. Whatmore (eds) Rural restructuring: global processes and their responses. London: David Fulton, pp.21-44.

Narotzky, Susana (2001) La antropología de los pueblos de España. Barcelona: Icaria.

Nash, Denninson (1992)[1977] "El turismo considerado como una forma de imperialismo". En Valene L. Smith (coord.) Anfitriones e invitados. Antropología del turismo. Madrid: Endymion, pp. 69-91.

Navarro, Javier (2007) “Las políticas de desarrollo rural de la Unión Europea”. En Sanz Cañada, J. (ed.) El Futuro del Mundo Rural. Madrid: Editorial Síntesis, pp.151-171.

Nogués, Antonio Miguel (1995) “Antropología y turismo rural. Una contingencia necesaria”. Gazeta de Antropología 11, artículo 8.

Nogués, Antonio Miguel (2016) "Entre el lentisco y la jara. Cinco conclusiones socioantropológicas sobre el turismo". Quaderns 32, pp.29-50.

Odermatt, Peter (2011) “¿Un caso de abandono? La política de representación: El caso de Cerdeña”. En Boissevain Jeremy (ed.). Lidiar con turistas. Reacciones europeas al turismo en masa. Barcelona. Ediciones Bellaterra, pp. 123-150.

Parque Nacional de Garajonay. Carta Europea de Turismo Sostenible. [Consultado el 2 de mayo de 2018].

Prats, Llorenc (1997) Antropología y Patrimonio. Barcelona: Editorial Ariel. 
Prats, Llorenc (2003) "Patrimonio + turismo = ¿desarrollo?". Pasos. Revista de turismo y Patrimonio Cultural, 1(2), pp. 127-136.

Prats, Llorenc (2005) "Concepto y gestión del Patrimonio Local". Cuadernos de Antropología Social 21 [Consultado el 21 de marzo de 2018].

Prats, Llorenc (2011) “La viabilidad turística del patrimonio". Pasos. Revista de turismo y Patrimonio Cultural 9(2), pp. 249-264.

Reyes, Antonio (1989) Estrategias Hidráulicas en la isla de La Gomera. Hermigua, Agulo y Valle Gran Rey (1900-1980). Santa Cruz de Tenerife: Museo etnográfico. Cabildo Insular de Tenerife y Cabildo Insular de La Gomera.

Roseberry, William (1989) Antropología e Historias. Ensayos sobre cultura, historia y economía política. Michoacan: El Colegio de Michoacán,A.C. http://www.colmich.edu. $\mathrm{mx} /$ computo/files/antropologiaHistoria13856.pdf

Ruiz, Esteban (2017) "Presentación. Claves del turismo de base local". Gazeta de Antropología 33(1), articulo 00.

Santana, Agustín (1997) Antropología y Turismo. Barcelona: Editorial Ariel.

Santana, Agustín (2003) “Turismo cultural, culturas turísticas”. Horizontes Antropológicos, $9(20)$.

Santana, Agustín (2008) "El turismo cultural. ¿Un negocio responsable?”. Estudios y perspectivas en turismo 17(4), 272-290.

Trapero, Maximiano (2000). Romancero General de La Gomera. Madrid: Cabildo Insular de La Gomera.

Turner, Louis y Ash, John (1991) La Horda Dorada. Madrid: Ediciones Endymion.

Urry, John (2006) [1995] Consuming Places. New York: Routledge.

Viera y Clavijo (2010) Descripción de la Gomera I y II. Santa Cruz de Tenerife: Ediciones Idea.

Wolf, Eric (2014) [1982] Europa y la gente sin historia. México: Fondo de Cultura Económica. 